\title{
Correction to: Static hedging of weather and price risks in electricity markets
}

\author{
Javier Pantoja Robayo ${ }^{1}$. Juan C. Vera²
}

Published online: 6 February 2021

(c) Springer Science+Business Media, LLC, part of Springer Nature 2021

\section{Correction to: Optimization and Engineering https://doi.org/10.1007/s11081-020-09581-0}

In the original publication of the article, Fig. 4 was published incorrectly. The correct figure is given below.

The original article can be found online at https://doi.org/10.1007/s11081-020-09581-0.

Juan C. Vera

j.c.veralizcano@tilburguniversity.edu

Javier Pantoja Robayo

jpantoja@eafit.edu.co

1 School of Economics and Finance, Universidad EAFIT, Medellin, Colombia

2 Tilburg School of Economics and Management, Tilburg University, Tilburg, The Netherlands 

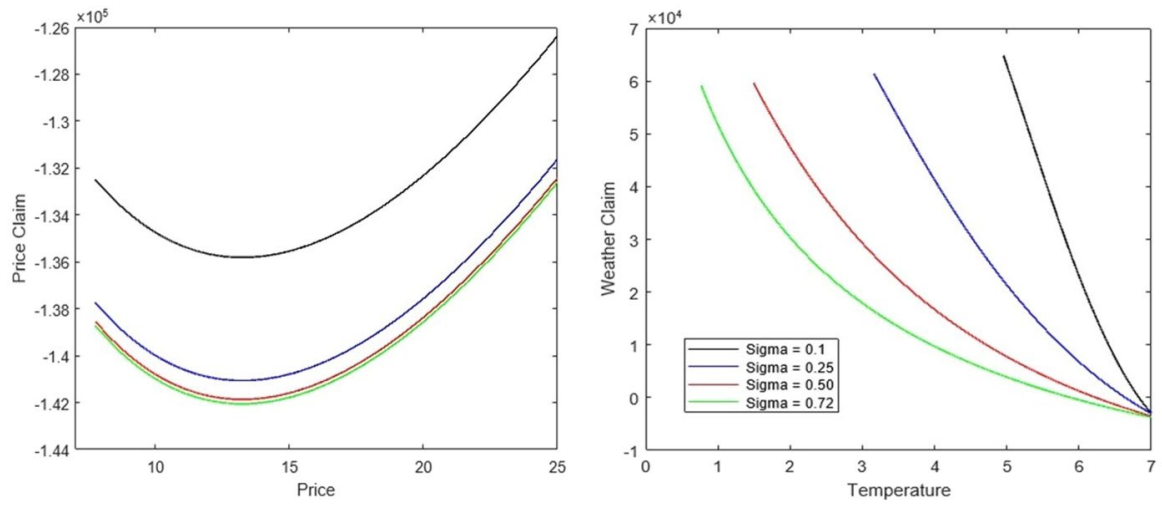

Fig. 4 Tails of price and weather contingent claims for different values of volatility sigma. Left: Price claim, right: Weather claim

Publisher's Note Springer Nature remains neutral with regard to jurisdictional claims in published maps and institutional affiliations. 